\title{
Relationship Between Childhood Peer Rejection and Aggression and Adolescent Delinquency Severity and Type Among African American Youth
}

\author{
Shari Miller-Johnson, John D. Coie, Anne Maumary-Gremaud, \\ JOHN LOCHMAN, AND ROBERT TERry
}

I nterpersonal and behavioral problems are common characteristics found in students with emotional or behavioral disorders (EBD; Farmer \& Hollowell, 1994; Kauffman, 1997). A disproportionately high number of youth receiving special education services for EBD also become involved with the juvenile justice system, and students with EBD are at high risk of becoming delinquent during adolescence (Peacock Hill Working Group, 1991). Thus, preventing and ameliorating delinquency in students with EBD is a primary concern for special education and mental health services (Bryant et al., 1995; Kauffman, 1997). By improving our understanding of the behavioral and social problems of students with EBD, we can increase the sensitivity and effectiveness of interventions to reduce and prevent later problems. Childhood peer rejection and aggression have been shown to contribute to adolescent delinquency (Coie, Lochman, Terry, \& Hyman, 1992; Kupersmidt, Coie, \& Dodge, 1990; Parker \& Asher, 1987).

Information on the relationship between peer rejection and aggression is critical for the assessment of risk for later problems. The National Agenda for Children with Serious Emotional

This prospective, longitudinal study examined peer rejection and aggression in childhood as predictors of the severity and type of delinquency during adolescence. Sociometric surveys were completed at third grade for a predominantly low-socioeconomic status, urban sample of African American boys and girls, and youth reports of delinquency were gathered at Grades 6, 8, and 10. Patterns of association between childhood peer rejection and aggression and delinquency severity varied by gender. For boys, the additive effect of childhood peer rejection and aggression was a strong predictor of more serious delinquency, whereas for girls only aggression predicted more serious delinquency. For boys, the combination of peer rejection and aggression was associated with felony assaults, and aggression was associated with a wide diversity of offenses during adolescence, whereas for girls only peer rejection predicted involvement in minor assault. Results are discussed in terms of the early starter pathway of antisocial behavior as it relates to peer rejection and aggression for boys, differing predictive patterns for girls, and implications for intervention with children with emotional and behavioral disorders.

Disturbance of the Office of Special Education Programs has highlighted the importance of identifying risk factors that contribute to the development of serious emotional disturbance (Wehby, Symons, \& Hollo, 1997). Recent theoretical models have emphasized the role of peer rejection and behavioral functioning as risk factor in the development of delinquency and antisocial behavior (Conduct Problems Prevention Research Group, 1992; Patterson, Capaldi, \& Bank, 1981). Children at risk for delinquency enter school with poorly developed social skills and high levels of disruptive and aggressive behaviors. These aversive, negative behav- iors lead to rejection by peers. Over time, these children increasingly are rejected by other children at school and, as a result, begin to interact with other youth who have been rejected. By age 10 or 12 , children who are chronically rejected initiate the early formation of deviant peer cliques. These social networks provide a fertile training ground for delinquent activities that begin early in the teenage years.

Knowledge of risk factors for antisocial behavior also has important implications for interventions to improve social relations among students with EBD (Walker et al., 1996). In particular, it suggests the need to develop strat- 
egies that address the peer group in order to promote peer ties that support prosocial behaviors and discourage affiliative ties that maintain problem behaviors (Farmer \& Hollowell, 1994). School systems are in an ideal position to provide such interventions, given their accessibility to a population with a high prevalence of students at risk for these difficulties (Bryant et al., 1995). Moreover, schools play an important role because of the presence of important socialization agents that are involved in children's lives. Thus, understanding associations between peer rejection and aggression and adolescent delinquency is relevant for accurate identification, assessment, and intervention of students with EBD.

Despite research supporting the role of aggressive behavior and peer rejection as predictors of delinquency, numerous issues remain to be studied. In many investigations of childhood aggression, peer rejection was not included as a predictor; therefore, it was not possible to compare and evaluate the predictive effects of both domains simultaneouly. Furthermore, not all children who are rejected by their peers are at increased risk for negative outcomes (Parker \& Asher, 1987). Studies of young men rejected by their peers have found a great deal of heterogeneity in the samples (Cillessen, van IJzendoorn, van Lieshout, \& Hartup, 1992; French, 1988). Some boys were characterized by aggressive, disruptive, and noncompliant behaviors, but others were characterized by shy, withdrawn, and introverted behaviors. However, in contrast with boys, where aggression differentiated subgroups, for girls the subgroups clustered by the degree of withdrawn, anxious behaviors (French, 1990).

Thus, for boys the combination of peer rejection and aggression may place a child at increased risk of later delinquency. In support of this premise, Bierman and Wargo (1995) found that aggressive boys who had been rejected by their peers evidenced the highest rates of behavior problems, in comparison with boys who were either aggressive only or had been rejected only. Similarly, Coie et al. (1992) found that both childhood aggression and peer rejection predicted early adolescent disorder. In a second study with the same sample (Coie, Terry, Lenox, Lochman, \& Hyman, 1995), boys who were aggressive and rejected by their peers displayed increasing levels of externalizing problems in Grades 6 through 10. In contrast, trajectories of externalizing problems for other boys either decreased or remained flat. However, patterns varied for girls, where the interaction of peer rejection and aggression did not predict poor adjustment. Thus, although the combination of peer rejection and aggression in boys may be a useful index for later delinquency, predictive patterns remain less clear for girls. Given differing socialization practices for girls and boys during childhood, peer processes may vary in their predictive role over time (Maccoby, 1990). Aggressive behavior during childhood is likely to be less physical for girls than for boys and may instead focus on issues of acceptance in smaller peer groups (Crick \& Grotpeter, 1995). Therefore, aggression may be a more salient predictor for boys, whereas peer rejection may be a more salient predictor for girls.

Antisocial behavior in girls has been sorely understudied (Zoccolillo, 1993). However, conduct problems are the second most common diagnosis among girls during the teenage years and appear equally stable over time for boys and girls (Robins, 1986). Diagnoses of conduct disorder peak for boys at age 10 , whereas diagnoses of conduct disorder among girls rise through age 16 (Cohen et al., 1993). Crime statistics (Office of Juvenile Justice and Delinquency Prevention, 1996) have indicated that, from 1989 to 1993 , the number of arrests of girls increased by $23 \%$, in comparison with an $11 \%$ increase for boys. Thus, identification of factors that predict delinquency in girls is a critical area for further study.

Another question that arises from the studies by Coie et al. $(1992,1995)$ is how peer rejection and aggression predict youth reports of delinquency, given the inherent biases in official arrest records. It has been estimated that police contacts represent only $3 \%$ to $10 \%$ of self-reported offenses (Elliot \& Voss, 1974). Arrests tend to focus on more serious antisocial behaviors that have a considerably lower base rate in the general population. In comparison, youth reports of delinquency are more sensitive to identifying a wide range of both serious and nonserious acts. Thus, predictive patterns may differ for arrest records and self-reported delinquency and for serious and nonserious offenses. This also raises the broader question of specialization of offending as it relates to the predictive role of childhood aggression and peer rejection during adolescence (i.e., do offenders specialize in a particular type of crime, such as property crimes, or do they commit a variety of crimes). Research has supported patterns of generality in offending behavior (Klein, 1984). For example, Capaldi and Patterson (1996) found no differences in family or child background variables between violent and nonviolent offenders. However, specialization has been found in some studies, although it appears to be superimposed on a larger pattern of generality in criminal offenses (Weiner, 1989). Moreover, the degree of specialization in offending may vary in subgroups at risk for adolescent delinquency. Thus, generality versus specificity in delinquent behavior-and how this relates to various predictors across development-is a key question.

A shortcoming of previous research is that most studies have focused on samples of White adolescents. Studies of mixed race samples have compared the relative influence of family and peer relations. Giordano, Cernkovich, and DeMaris (1993) found that Black youth reported lower levels of peer pressure and need for peer approval in comparison with White youth. Similarly, Tolson and Urberg (1993) found that African American youth, in comparison with White youth, assigned higher levels of importance to involvement in family and school activities and lower levels of importance to peer involvement and misconduct activities. Therefore, peer relations may not be as salient a predictor of delinquency for African American youth. 
The purpose of this study was to examine peer rejection and aggression as predictors of the severity and type of adolescent delinquency. These questions were examined in an urban sample of African American boys and girls participating in a prospective, longitudinal investigation. Measures included peer ratings of rejection and aggression in third grade and youth reports of delinquency in sixth, eighth, and tenth grades. Three questions were explored:

What is the association between peer rejection and aggression and youth reports of serious and nonserious delinquency across adolescence?

How are peer rejection and aggression associated with specific types of delinquency?

Are there differences between boys and girls in the relationship between childhood peer rejection and aggression and adolescent delinquency?

\section{Method}

\section{Participants}

Participants were part of an ongoing longitudinal study of the development of antisocial behavior from childhood to young adulthood (Coie et al., 1992; Coie et al., 1995). Three cohorts of participants were recruited in 1984, 1985, and 1986 (Cohort A: $n=588$, Cohort B: $n=559$, Cohort $\mathrm{C}: n=602$ ). Measures of peer social status and social behavior were administered to all third graders across 12 elementary schools $(N=1,749)$.

Representative samples of each of the third-grade cohorts were selected randomly from the four nonrejected peer status groups (i.e., average, controversial, neglected, popular; see Coie \& Dodge, 1983, for scoring details) in numbers proportional to their population distribution from sociometric data. Attempts were made to locate all participants rejected by peers, due to research questions about the role of peer rejection and later adjustment. This subsample $(N=622)$ participated in lon- gitudinal follow-up at 2-year intervals across adolescence, beginning in sixth grade. Assessments were completed by trained staff in the home, and youth were interviewed without parents or other individuals present. The participants in this study included those individuals with complete data at Grades 6, 8, and 10 ( $n=327 ; 50.2 \%$ boys). Attrition information is provided later in this article. The population served by the Durham city schools was predominantly African American (90\%) and of low- to lowersocioeconomic status $(65 \%$ of the children in the school system were eligible for the free or reduced school lunch program). Only African American students were included in the longitudinal follow-up, given problems interpreting sociometric data on children who are in an extreme minority of a school population (Kupersmidt \& Coie, 1990).

\section{Measures}

Sociometric Survey. Sociometric surveys were conducted in third-grade classrooms. Children were provided with a roster of all the children in their grade and asked to nominate the three students that they liked most and liked least. Children were also provided with a list of behavioral descriptions and asked to nominate the three children in their grade who best fit each description. The descriptor for "starts fights, hits other children, or says mean things to them" was used as a measure of aggression. Children were allowed to vote for peers of both genders in order to increase stability of measurement (Terry \& Coie, 1991). Scores were calculated for each child using ratings from all students in a grade and standardized within schools. Following procedures described by Coie and Dodge (1983), children were assigned to either the rejected or the nonrejected peer status group. Of the total participants in this study, 94 ( $51.1 \%$ boys) were rated as rejected by their peers in third grade.

As expected, examination of the "starts fights" variable showed a higher proportion of boys at the upper portion of the distribution. Therefore, this variable was standardized by gender to guar- antee identification of similar prevalence rates for boys and girls. Aggressive participants were defined as those students who received a standardized "starts fights" score greater than 1.0 standard deviation. In the current sample, a total of 56 participants ( $44.6 \%$ boys) were rated as aggressive. The dichotomous rejection and aggression variables were then crossed, resulting in a child's membership in one of four categories:

$$
\begin{aligned}
& \text { - nonrejected-nonaggressive } \\
& \text { ( } n=208 ; 48 \% \text { boys }) \\
& \text { rejected-nonaggressive ( } n=63 \text {; } \\
& 60 \% \text { boys), } \\
& \text { - nonrejected-aggressive }(n=25 ; \\
& 60 \% \text { boys), and } \\
& \text { - rejected-aggressive ( } n=31 ; 32 \% \\
& \text { boys). }
\end{aligned}
$$

Juvenile Delinquency. Participants were interviewed using the National Youth Survey (NYS; Elliot, Huizinga, \& Ageton, 1985; Elliot, Huizinga, \& Menard, 1989), which assesses youth reports of involvement in delinquent behaviors that are representative of the range of serious and nonserious offenses reported in the Uniform Crime Reports (UCR). The NYS was developed as part of a longitudinal study of delinquency using a national probability sample of U.S. households of youth ages 11 to 17 . Test-retest reliabilities were reported to range from .7 to .9 . Validity was confirmed through (a) detailed follow-up questions to determine if items were generating appropriate responses, (b) investigation of behaviors that were considered too trivial to be considered delinquent, (c) comparison of official arrest records and self-reported offenses; and, (d) examination of the pattern of associations between the self-report scales and predictor measures (see Huizinga \& Elliot, 1986, for more detailed information). Participants were asked how often they were involved in an offense over the last year.

Eight scales, divided into three types, were used:

- serious offenses scale, which consists of serious index offenses that are part of the FBI's measure 
of serious crime and include felony theft, felony assault, and robbery offenses;

- nonserious scale, which includes minor, nonserious acts, such as stealing something worth less than $\$ 50$, hitting a teacher or parent, and damaging property; and

- offense-specific scales, which are six scales involving homogenous groupings of offense items in terms of the nature and severity of the act committed. These six groups were minor theft, felony theft, minor assault, felony assault, vandalism, and robbery.

Scales were coded dichotomously (i.e., whether or not a participant reported having committed any of the specific offenses on a given scale; see Note).

\section{Attrition}

Attrition was due primarily to the inability to locate participants. Moreover, a small number of participants refused to be interviewed. As stated earlier, 622 participants were included in the longitudinal follow-up sample, and 53\% had complete data at Grades 6, 8, and 10 . Youth participation rates were $84 \%$, $79 \%$, and $73 \%$ at Grades 6, 8, and 10 . To test for differential attrition, sociometric functioning at Grade 3 was compared for participants with complete NYS data at Grades 6, 8, and 10 to those with partially missing data. Attrition did not vary by gender. Participants with incomplete data displayed a trend toward higher levels of aggression in comparison to participants with complete data, $t(584)=-1.85, p<.10$. Additional analyses by gender found that this pattern was significant for boys only, $t(298)=$ $-2.24, p<.05$, with boys who were aggressive in third grade being more likely to have incomplete data. This apparent nonrandom attrition is discussed later in the article. Analyses also compared sixth-grade scores on NYS scales for participants with complete data at three time points versus participants with incomplete data. Results were nonsignificant, with the exception of rob- bery, $\chi^{2}(1, N=518)=3.92, p<.05$, where participants with complete data reported a higher rate of involvement in this offense. Comparison by gender indicated that this pattern was significant for boys only, $\chi^{2}(1, N=268)=5.73$, $p<.05$.

\section{RESULTS}

Descriptive information is provided on the serious, nonserious, and offensespecific scales of the NYS for boys and girls. Log linear regression analyses are reported, with third-grade rejection, aggression, and the interaction of rejection with aggression as predictor variables. Separate analyses were carried out for the serious and nonserious offense scales and for each of the six offense-specific scales as outcome variables at Grades 6, 8, and 10. The full saturated model was first fitted, including all main effects and interactions. Nonsignificant effects were then removed, and final models were reported. Exploratory analyses were done with boys and girls combined, and gender interaction effects were shown in predicting all but two of the scales. Consequently, analyses reported here were done separately by gender.

\section{Descriptive Information: Offense Scales}

For serious offenses, rates were significantly higher for boys than for girls at Grade $6, \chi^{2}(1, N=327)=9.34, p<.01$, and Grade $8, \chi^{2}(1, N=327)=11.01$, $p<.01$. For boys, serious offenses remained steady at Grades 6,8 , and 10 $(30.1 \%, 30.7 \%$, and $27.6 \%$, respectively), whereas for girls levels were lower at Grades 6 and 8 but then rose at Grade $10(15.9 \%, 15.2 \%$, and $21.3 \%$, respectively). Nonserious offenses rose over time and achieved rates considerably higher than rates for serious offenses for both boys and girls. Rates varied by gender at Grade 6, $\chi^{2}(1, N=327)=$ $4.70, p<.05$, and displayed a trend toward significance at Grade $10, \chi^{2}(1$, $N=327)=3.80, p<.10$.

For boys, nonserious offenses rose from $46.0 \%$ at Grade 6 to $51.5 \%$ and
$60.1 \%$ at Grades 8 and 10 , respectively. Rates of involvement in nonserious offenses for girls rose from $34.1 \%$ at Grade 6 to $43.9 \%$ and $49.4 \%$ at Grades 8 and 10 , respectively. Rates of involvement and comparisons by gender for the offense-specific scales are shown in Table 1. For most scales, boys reported significantly higher rates, and gender differences became more apparent after the sixth grade. In terms of developmental patterns, involvement in minor theft, minor assault, and felony theft increased over time for boys, whereas involvement in vandalism decreased over time for both boys and girls.

\section{Peer Rejection and Aggression as Predictors of Offense Seriousness}

Log linear analyses examined peer rejection and aggression at Grade 3 as predictors of the serious and nonserious scales at Grades 6, 8, and 10. For boys, aggression was a significant predictor of both the serious, $\chi^{2}(1, N=163)=7.56$, $p<.01$, and the nonserious, $\chi^{2}(1, N=$ $163)=15.55, p<.001$, scales. Furthermore, the interaction of rejection with aggression was a significant predictor of serious, $\chi^{2}(1, N=163)=7.73, p<.01$, and nonserious, $\chi^{2}(1, N=163)=5.82$, $p<.05$, offending. For girls, only aggression was a significant predictor of serious offenses, $\chi^{2}(1, N=164)=4.02$, $p<.05$. All variables were nonsignificant in predicting nonserious offending for girls.

Predicted probabilities were estimated to further examine the nature of the effects of peer rejection and aggression for boys. For the nonserious scale, the likelihood of committing an offense was $45 \%$ for participants who were both rejected by peers and aggressive in third grade. Probabilities were lower for participants who were aggressive but not rejected $(41 \%)$, followed by participants who were neither rejected nor aggressive (39\%), and finally by participants who were rejected but not aggressive (34\%). Therefore, the two aggressive groups displayed the highest likelihood of committing a nonserious offense. However, 
a significantly higher probability was exhibited for the combination of peer rejection and aggression.

For serious offenses, the pattern of predicted probabilities was more distinct for participants who were both rejected and aggressive in third grade in comparison with other groups. Specifically, the likelihood of committing a serious offense was $41 \%$ for rejectedaggressive participants, whereas probabilities for other groups were lower and fairly even (rejected-nonaggressive, $30 \%$; nonrejected-aggressive, 33\%; nonrejectednonaggressive, $34 \%$ ). Thus, for predicting serious offenses, the main effect for aggression appeared to be accounted for by the interaction of aggression and peer rejection in third grade.

\section{Peer Rejection and Aggression as Predictors of Specific Offenses}

The results from log linear analyses of peer rejection and aggression as predictors of offense-specific scales are reported in Table 2. For boys, aggression significantly predicted a wide range of serious and nonserious offenses, including minor assault, felony assault, felony theft, vandalism, and robbery; peer rejection was a significant predictor of felony assault and minor theft. Effects for peer rejection and minor theft and for aggression and robbery were in an unanticipated direction, with higher levels of rejection or aggression associated with lower offending levels, as indicated by an odds ratio less than 1.0. All other effects were in the expected direction. The interaction of rejection and aggression provided additional significant prediction of felony assault. For girls, rejection was a significant predictor of minor assault. Prediction of all other offense-specific scales for girls was nonsignificant.

Predicted probabilities were estimated to examine the nature of the interaction between peer rejection and aggression in predicting felony assaults for boys. The likelihood of involvement was similar for participants in the nonrejected-nonaggressive (32\%),

TABLE I

Involvement in Offense-Specific Scales at Grades 6, 8, and 10, by Gender

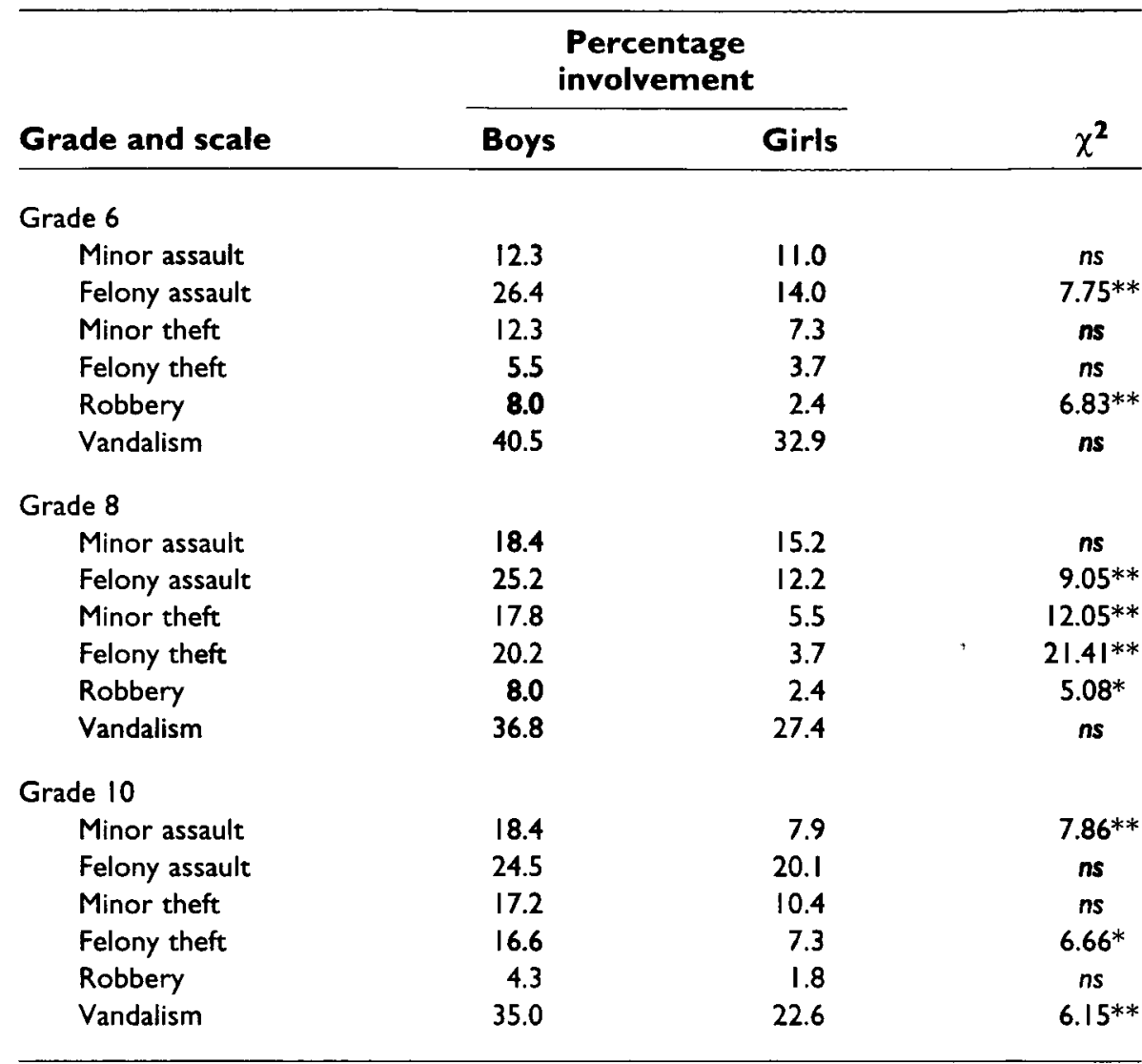

$*_{p}<.05 . * * p<.01$

nonrejected-aggressive $(30 \%)$, and rejected-nonaggressive (31\%) groups. However, the likelihood of involvement in felony assaults increased to $40 \%$ for boys in the rejected-aggressive group. Therefore, the main effects for aggression appeared to be due to the interaction of rejection and aggression.

\section{DISCUSSION}

The purpose of this study was to examine the influence of peer rejection and aggression in third grade on the severity and type of delinquency in sixth, eighth, and tenth grades. The sample consisted of urban, African American youth and, as such, diversified the populations in which these questions have been explored. The results are relevant to efforts to develop effective interventions to prevent antisocial behavior in school-age youth (Walker et al., 1996).
Problematic peer relations are an important contributor to delinquency. By understanding the social and behavioral functioning of students with EBD, we can develop effective programs that are sensitive to these risk factors. The results of this study showed that the combination of peer rejection and aggression was a significant predictor of serious and nonserious offending for boys. For girls, only aggression during childhood predicted serious offenses. In terms of specific offenses, childhood aggression predicted a wide diversity of delinquency for boys. Furthermore, being rejected by peers and being highly aggressive in childhood was predictive of serious interpersonal, felony assault offenses for boys. Only peer rejection predicted minor assault offenses for girls.

These findings confirm earlier studies that showed the additive strength of peer rejection and aggression as a pre- 
TABLE 2

Log-Linear Prediction of Offense-Specific Scales at Grades 6, 8, and 10 from Grade 3 Peer

Rejection and Aggression

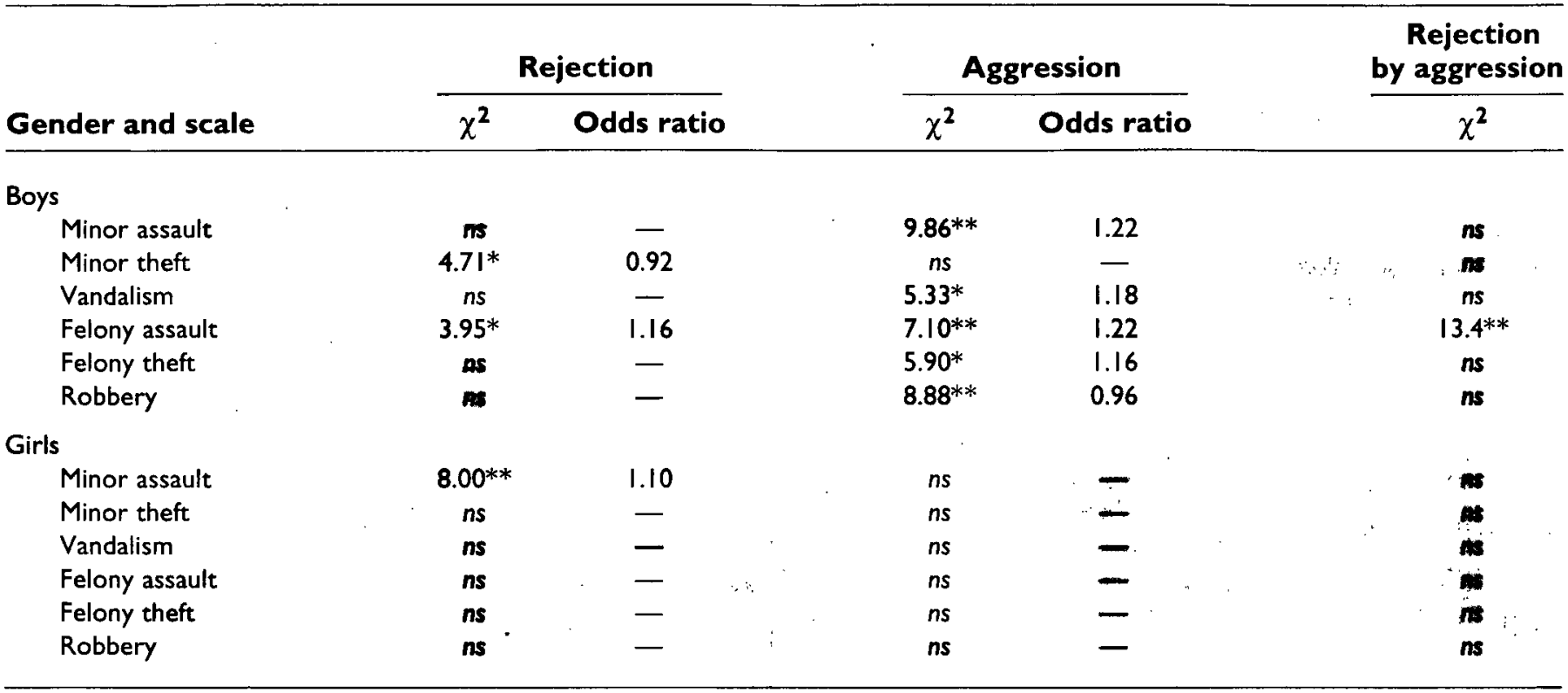

Note. Odds ratios are reported only for significant pairwise comparisons (i.e., main effects for rejection and aggression)

$* p<.05 . * * p<.01$.

dictor of negative outcomes, at least for boys (Bierman \& Wargo, 1995; Coie et al., 1992; Coie et al., 1995), supporting the premise that children who are rejected by their peers and are highly aggressive best fit early starter models of antisocial behavior (Coie \& Lenox, 1994; Moffitt, 1993; Patterson et al., 1991). It is speculated that this group accounts for a disproportionate amount of offending that persists into adulthood. Furthermore, early-starter children exhibit higher levels of serious offending and display a wider variety and more extreme forms of antisocial behaviorsparticularly those involving interpersonal violence (Tolan \& Thomas, 1995).

Regarding the question of specialization versus generalization of offending, our findings suggest a mixed pattern. Childhood aggression was associated with an array of offenses for boys and, therefore, supports a broader pattern of generality in criminal offending. The combination of peer rejection and aggression was associated specifically with felony assaults during the teenage years. Previous research has shown that rejectedaggressive boys have difficulty inhibit- ing aggressive behavior in peer interactions (Coie, Dodge, \& Kupersmidt, 1990). Furthermore, peers may respond with counteraggression, which may lead to an escalation in aggressive interactions and a negative spiral of continued interpersonal problem behaviors (Coie et al., 1990). Therefore, deficits found in rejected-aggressive boys may promote serious, interpersonal assaultive behavior such as gang fights and strong-arming others.

Prediction of adolescent offending in girls was of particular interest in this study. The interaction of peer rejection and aggression did not predict serious offending for girls, as it did for boys, and there were very few significant predictive patterns for girls. A number of speculations can be made about the lack of findings for girls. It may be that the early-starter model does not apply as well to girls in understanding the developmental progression of antisocial behavior. Indeed, theories of dual developmental pathways were developed based on samples that were composed exclusively of boys (Loeber, 1990; Moffitt, 1993; Patterson et al., 1991). Aggressive, disruptive, impulsive behaviors that characterize the early-starter pattern also may not occur at high enough base rates in girls to serve as a marker for early conduct problems. Aggression in childhood for girls may be associated with other outcomes, such as teenage childbearing. Indeed, in a study of girls from the same sample, girls who were highly aggressive in childhood were at increased risk to have more children and to become teenage parents at earlier ages (MillerJohnson et al., 1999). The experience of rejection also seems to differ by gender. Among boys, aggressive behavior discriminated rejected status from other peer status groups, whereas among girls, withdrawal differentiated rejected and nonrejected status (Coie et al., 1990; Coie et al., 1992). Therefore, girls' experience of peer rejection may be related to social isolation that would be unlikely to lead to early formation of deviant peer cliques, as seems to be the case with boys.

The findings from this study show that models of peer rejection and aggression developed from samples of White youth (Moffitt, 1993; Patterson 
et al., 1991) generalize to this sample of urban, African American youth. Therefore, peer relations appear to be important in understanding the development of antisocial behavior for African American youth, at least for boys. These youth may be exposed to other stressors, including poverty, crime, unemployment, and discrimination. However, although it is important to recognize them as important contributors, these other variables may be less amenable to change. Therefore, results showing the significance of peer relations are promising in terms of providing suggestions to improve the effectiveness of intervention strategies. Moreover, given the literature showing the importance of family ties for African American youth, the operative question may not so much be the relative importance of peer and parent influences but rather in what ways family characteristics might serve as protective factors in buffering against delinquency.

\section{Limitations}

A number of limitations are noted about this study. Attrition analyses suggested that boys who were highly aggressive in third grade were disproportionately missing from follow-up assessments. Thus, adolescents at highest risk for reporting serious offenses were not included in the analyses. Furthermore, the number of highly aggressive boys was likely smaller than if all participants had been available for follow-up. The probable effect of this attrition would be to lower overall rates of offending in the sample, as boys who were highly aggressive in third grade would be at higher risk for delinquency in adolescence. Therefore, the nonrandom nature of the attrition may potentially have obfuscated predictive patterns between childhood aggression and later offending. These results should be interpreted with caution, as results might have differed with a fully representative sample. However, in spite of this attrition, aggression was highly predictive of a wide range of delinquency scales for boys.

An additional limitation pertains to the small sample size and low statisti- cal power, particularly as it relates to the number of participants who were both rejected and aggressive. This may account for the lack of significant findings for girls. Future research would benefit from additional studies with larger samples to further explore these questions. Another limitation pertains to the use of self-report delinquency scales. These measures generally avoid shortcomings associated with official data, such as the selective biases and unrepresentativeness of the sample. However, potential problems with self-report measures include deliberate falsification, recall error, classification errors, and the reporting of trivial events (Elliott et al., 1989).

\section{Implications}

The current study has several implications for interventions for children with EBD. Identifying characteristics of children that predict antisocial behavior helps to determine whom to target for preventive interventions. Moreover, the literature on characteristics of rejectedaggressive children provides valuable information on intervention strategies for these youth. There is a need to closely fit intervention strategies with known information. Historically, social skill training has focused on increasing positive behaviors such as increased peer interaction and improved play skills. However, these interventions tend to ignore negative behaviors such as aggression and disruption that are aversive to peers.

Interventions also need to address the larger cognitive, interpersonal, and emotional deficits associated with peer rejection and aggression. Rejected-aggressive boys display a diversity of problem behaviors, including higher levels of inattention, verbal aggression, and hyperactivity, and lower levels of prosocial skills (Bierman, Smoot, \& Aumiller, 1993). Rejected-aggressive boys are prone to develop hostile attributions in ambiguous social situations and to be hypervigilant to hostile cues in their environment (Dodge \& Feldman, 1990). They may respond aggressively, have difficulty recognizing strong emotions, and have problems modulating their behavioral responses. These youth may also tend to overestimate their own social competence and be less aware of how they are viewed by others (Zakriski \& Coie, 1996).

Rejected-aggressive youth also tend to have problems negotiating the social interactional demands associated with peer interchanges. They may display deficits in skills necessary for peer play, such as the ability to positively attend to others, to display cooperative behaviors, to communicate clearly, to follow rules, and to negotiate conflicts (Bierman, Greenberg, \& Conduct Problems Prevention Research Group, 1996; Coie, 1996). Moreover, the negative attributes of rejected-aggressive youth may limit opportunities for positive interactions. Due to their negative behaviors, they may be victimized by peers or be left out of activities. Therefore, other peers are less able to serve as positive role models and to provide feedback about inappropriate interpersonal behavior. Peer responses may also reinforce the behaviors of rejected-aggressive youth either by attending to the behaviors or by complying to demands. Other peers may develop negative attitudes and expectations about rejected-aggressive children and, consequently, treat them differently than socially accepted peers (Hymel, Wagner, \& Butler, 1990). These factors converge to create a context that promotes and escalates antisocial behavior over time.

Social skills training needs to address the multiple domains of functioning for rejected-aggressive children, including behavioral, social-cognitive, interpersonal, and affective aspects. Groups should include small numbers of highrisk students in order to provide an intensive focus on skill deficits in the domains of play and prosocial behavior. This setting also allows for practice and rehearsal of skills in the areas of self-control, anger coping, emotion regulation, and social problem solving (Coie \& Krehbiel, 1990; Lochman \& Wells, 1996). Activities such as board games, role play, and use of visual and other multimedia tools to present key concepts can foster interest and participation. 
Sessions should also include opportunities for guided rehearsal and practice of skills and provide corrective feedback about members' behavioral functioning.

An additional component of social skills programming can involve peer pairing, in which a high-risk child takes part in a guided play session with another student (Bierman et al., 1996). This experience provides an opportunity for high-risk children to exhibit positive social skills in a structured setting and fosters mutually rewarding social exchanges. Staff can also cue appropriate use of social skills learned in a smaller group setting, thereby further reinforcing their use in a different context. Skills can then be generalized to peers outside of the small group setting and to the larger school environment. By providing a positive interaction with other peers, this can improve the attitudes of other students toward rejectedaggressive youth and increase their social acceptance.

Schools are a sensible place to provide such interventions for a number of reasons. Educational settings provide accessibility to large numbers of students in order to screen and identify youth at risk for later difficulties. Children who will ultimately become delinquent can be reliably identified early in the school years (Loeber, 1990). Furthermore, the school system is a representative sample of a given geographic area. Through early identification and provision of preventive services, it is hoped that we can reduce deficits that start a child on a negative pathway toward delinquency.

A number of future research issues are suggested by these findings. Further study of the prediction of developmental processes leading to conduct problems in girls is warranted. Correlates of antisocial behavior may not be the same for boys and girls, and there is a need to expand the standards used to assess conduct problems (Zahn-Waxler, 1993). One avenue to explore is the way in which aggressive behavior is displayed in girls. Aggression may be exhibited in more subtle forms that focus on relational aspects, as opposed to overt physical displays such as fighting and picking on other children (Crick \& Grotpeter, 1995). Furthermore, base rates of delinquency increase for girls during adolescence, compared with low rates during childhood (Cohen et al., 1993). Therefore, processes thought to be associated with late starting delinquency, such as deviant peer associations, may play a more prominent role for girls.

Other issues for further study include continued longitudinal investigation of the role of aggression and peer rejection throughout development. Do these characteristics continue to be associated with antisocial behavior into young adulthood, or is there a developmental threshold after which these factors are no longer salient predictors? It would also be useful to examine other outcomes of peer rejection and aggression that are developmentally relevant to young adulthood, such as obtaining steady and gainful employment, establishing romantic relationships, and having a family.

In summary, the combination of peer rejection and aggression in childhood was an important contributor to serious and nonserious offending in adolescence among boys, whereas for girls fewer predictive patterns were shown. These findings underscore the developmental processes associated with being rejected by peers and being highly aggressive in childhood and their relationship to subsequent delinquency for boys. The findings also emphasize the importance of addressing these interpersonal and behavioral characteristics in preventive interventions designed for children with EBD.

\section{About the Authors}

SHARI MILLER-JOHNSON, PhD, is a research fellow at the Frank Porter Graham Child Development Center at the University of North Carolina, Chapel Hill. JOHN D. COIE, PhD, is a professor in the Department of Psychology at Duke University. ANNE MAUMARY-GREMAUD, MS, is a statistician in the Department of Psychology at Duke University. JOHN LOCHMAN, $\mathrm{PhD}$, is a professor in the Depart- ment of Psychology at the University of Alabama. ROBERT TERRY, PhD, is an assistant professor in the Department of Psychology at the University of Oklahoma. Address: Shari Miller-Johnson, Frank Porter Graham Child Development Center, 521 S. Greensboro St., Carrboro, NC 27510; e-mail: sharimj@unc.edu

\section{Authors' Notes}

1. This research was supported by Grant Nos. R01 MY390140 and K05MH00797 from the Prevention Branch of the National Institute of Mental Health.

2. We are grateful to the staff and children of the Durham, North Carolina, schools for their cooperation in this longitudinal study.

3. This study was done while the first author was a research associate in the Department of Psychology at Duke University.

\section{Note}

Responses were initially coded to indicate how many times in the last year participants had committed a particular offense. Exploratory analyses indicated a high degree of skewness. Consequently, analyses employing the General Linear Model (Cohen \& Cohen, 1983) using a continuous outcome variable could not be employed due to violation of the assumption of normality, and all scales were coded dichotomously.

\section{References}

Bierman, K. L., Greenberg, M. T., \& Conduct Problems Prevention Research Group. (1996). Social skills training in the Fast Track program. In R. D. Peters \& R. J. McMahon (Eds.), Preventing childhood disorders, substance abuse, and delinquency (pp. 65-89). Thousand Oaks, CA: Sage.

Bierman, K. L., Smoot, D. L., \& Aumiller, K. (1993). Characteristics of aggressiverejected, aggressive (nonrejected) and rejected (nonaggressive) boys. Child Development, 64, 139-151.

Bierman, K. L., \& Wargo, J. B. (1995). Predicting the longitudinal course associated with aggressive-rejected, aggressive (nonrejected), and rejected (nonaggressive) status. Development and Psychopathology, 7, 669-683.

Bryant, E. S., Rivard, J. C., Addy, C. L., Hinkle, K. T., Cowan, T. M., \& Wright, G. (1995). Correlates of major and minor 
offending among youth with severe emotional disturbance. Journal of Emotional and Behavioral Disorders, 3, 76-84.

Capaldi, D., \& Patterson, G. (1996). Can violent offenders be distinguished from frequent offenders: Prediction from childhood to adolescence. Journal of Research in Crime and Delinquency, 33, 206-231.

Cillessen, A. H. N., Van IJzendoorn, H. W. V., Van Lieshout, F. M., \& Hartup, W. (1992). Heterogeneity among peer-rejected boys: subtypes and stabilities. Child Development, 63, 893-905.

Cohen J., \& Cohen, P. (1983). Applied multiple regression/correlation analyses for the behavioral sciences ( 2 nd ed.). Hillsdale, NJ: Erlbaum.

Cohen, P., Cohen, J., Kasen, S., Velez, C. N., Hartmark, C., \& Johnson, J. (1993). An epidemiological study of disorders in late childhood and adolescence-I. Ageand gender-specific prevalence. Journal of Child Psychology and Psychiatry, 34, 851-867.

Coie, J. D. (1996). Prevention of violence and antisocial behavior. In R. D. Peters \& R. J. McMahon (Eds.), Preventing childhood disorders, substance abuse, and delinquency (pp. 1-8). Thousand Oaks, CA: Sage.

Coie, J. D., \& Dodge, K. A. (1983). Continuities and changes in children's social status: A five-year longitudinal study. Child Development, 59, 815-829.

Coie, J. D., Dodge, K. A., \& Kupersmidt, J. B. (1990). Peer group behavior and social status. In S. A. Asher \& J. D. Coie (Eds.), Peer rejection in childhood (pp. 17-59). New York: Cambridge University Press.

Coie, J. D., \& Krehbiel, G. K. (1990). Adapting intervention to the problems of aggressive and disruptive rejected children. In S. R. Asher \& J. D. Coie (Eds.), Peer rejection in childhood (pp. 309-337). New York: Cambridge University Press.

Coie, J. D., \& Lenox, K. (1994). The development of antisocial individuals. In D. C. Fowles, P. Sutker, \& S. H. Goodman (Eds.), Progress in experimental personality and psychopathology research (pp. 45-72). New York: Springer Verlag.

Coie, J. D., Lochman, J., Terry, R., \& Hyman, C. (1992). Predicting early adolescent disorder from childhood aggression and peer rejection. Journal of Consulting and Clinical Psychology, 60, 783-792.

Coie, J. D., Terry, R., Lenox, K., Lochman, J., \& Hyman, C. (1995). Childhood peer rejection and aggression as predic- tors of stable patterns of adolescent disorder. Development and Psychopathology, 7, 697-713.

Conduct Problems Prevention Research Group. (1992). A developmental and clinical model for the prevention of conduct disorder: The FAST Track Program. Development and Psychopathology, 4, 509527.

Crick, N., \& Grotpeter, J. (1995). Relational aggression, gender, and socialpsychological adjustment. Child Development, 66, 710-722.

Dodge, K. A., \& Feldman, E. (1990). Issues in social cognition and sociometric status. In S. A. Asher \& J. D. Coie (Eds.), Peer rejection in childhood (pp. 119-154). New York: Cambridge University Press. Elliott, D. S., Huizinga, D., \& Ageton, S. S. (1985). Explaining delinquency and drug use. Newbury Park, CA: Sage.

Elliot, D. S., Huizinga, D., \& Menard, S. (1989). Multiple problem youth: Delinquency, substance use, and mental health problems. New York: Springer Verlag.

Elliott, D. S., \& Voss, H. L. (1974). Delinquency and dropout. Lexington, MA: D.C. Heath.

Farmer, T. W., \& Hollowell, H. J. (1994). Social networks in mainstream classrooms: Social affiliations and behavioral characteristics of students with EBD. Journal of Emotional and Behavioral Disorders, 2, 143-155.

French, D. C. (1988). Heterogeneity of peerrejected boys: Aggressive and nonaggressive subtypes. Child Development, 59, 976-985.

French, D. C. (1990). Heterogeneity of peerrejected girls. Child Development, 61, 2028-2031.

Giordano, P. C., Cernkovich, S. A., \& DeMaris, A. (1993). The family and peer relations of black adolescents. Journal of Marriage and the Family, 55, 277-287.

Huizinga, D., \& Elliott, D. S. (1986). Reassessing the reliability and validity of selfreport delinquency measures. Journal of Quantitative Criminology, 2, 293-327.

Hymel, S., Wagner, E., \& Butler, L. J. (1990). Reputational bias: View from the peer group. In S. R. Asher \& J. D. Coie (Eds.), Peer rejection in childhood (pp. 156-186). New York: Cambridge University Press.

Kauffman, J. M. (1997). Characteristics of emotional and behavioral disorders of children and youth. Upper Saddle River, NJ: Prentice Hall.

Klein, M. W. (1984). Offense specialization and versatility among juveniles. British
Journal of Criminology, 24, 185-194.

Kupersmidt, J. B., \& Coie, J. D. (1990). Preadolescent peer status, aggression, and school adjustment as predictors of externalizing problems in adolescence. Child Development, 61, 1350-1362.

Kupersmidt, J. B., Coie, J. D., \& Dodge, K. A. (1990). The role of poor peer relationships in the development of disorder. In S. R. Asher \& J. D. Coie (Eds.), Peer rejection in childhood (pp. 274-305). New York: Cambridge University Press.

Lochman, J. E., \& Wells, K. C. (1996). A social-cognitive intervention with aggressive children: Prevention effects and contextual implementation issues. In R. D. Peters \& R. J. McMahon (Eds.), Preventing childhood disorders, substance abuse, and delinquency (pp. 90-110). Thousand Oaks, CA: Sage.

Loeber, R. (1990). Development and risk factors of juvenile antisocial behavior and delinquency. Clinical Psychology Review, $1,1-41$.

Maccoby, E. E. (1990). Gender and relationships: A developmental account. American Psychology, 50, 513-520.

Miller-Johnson, S., Winn, D. M., Coie, J. D., Hyman, C., Terry, R., Lochman, J., \& Maumary-Gremaud, A. (1999). Parenthood during the teen years: A developmental perspective on risk factors for childbearing. Development and Psychopathology, 11, 85-100.

Moffitt, T. E. (1993). Adolescence-limited and life-course-persistent antisocial behavior: A developmental taxonomy. Psychological Review, 100, 674-701.

Office of Juvenile Justice and Delinquency Prevention. (1996). Female offenders in the juvenile justice system. (Published by the National Center for Juvenile Justice)

Parker, J. G., \& Asher, S. R. (1987). Peer relations and later personal adjustment: Are low-accepted children at risk? Psychological Bulletin, 102, 357-389.

Patterson, G. R., Capaldi, D. M., \& Bank, L. (1991). An early starter model for predicting delinquency. In D. J. Pepler \& K. H. Rubin (Eds.), The development and treatment of childhood aggression (pp. 139-168). Hillsdale, NJ: Erlbaum.

Peacock Hill Working Group. (1991). Problems and promises in special education and related services for children and youth with emotional or behavioral disorders. Behavioral Disorders, 16, 299-313.

Robins, L. N. (1986). The consequences of conduct disorder in girls. In D. Olweus, $M$. R. Yarrow, \& J. Block (Eds.), The develop- 
ment of antisocial and prosocial behavior (pp. 385-414). New York: Academic Press.

Terry, R., \& Coie, J. D. (1991). A comparison of methods for defining sociometric status among children. Developmental Psychology, 27, 867-880.

Tolan, P., \& Thomas, P. (1995). The implications of age of onset for delinquency risk II: Longitudinal data. Journal of $A b$ normal Child Psychology, 23, 157-181.

Tolson, J. M., \& Urberg, K. A. (1993). Similarity between adolescent best friends. Journal of Adolescent Research, 8, 274-288.

Walker, H. M., Horner, R. H., Sugai, G.,
Bullis, M., Sprague, J. R., Bricker, D., \& Kaufman, J. M. (1996). Integrated approaches to preventing antisocial behavior patterns among school-age children and youth. Journal of Emotional and Behavioral Disorders, 4, 194-209.

Wehby, J. H., Symons, F. J., \& Hollo, A. (1997). Promote appropriate assessment. Journal of Emotional and Behavioral Disorders, 5, 45-54.

Weiner, N. A. (1989). Violent criminal careers and violent career criminals: An overview of the research literature. In N. A. Weiner \& M. E. Wolfgang (Eds.), Vio- lent crime, violent criminals (pp. 35-138). Newbury Park, CA: Sage.

Zahn-Waxler, C. (1993). Warriors and worriers: Gender and psychopathology. Development and Psychopathology, 5, 79-90.

Zakriski, A. L., \&. Coie, J. D. (1996). A comparison of aggressive-rejected and nonaggressive-rejected children's interpretations of self-directed and otherdirected rejection. Child Development, 67 , 1048-1070.

Zoccolillo, M. (1993). Gender and the development of conduct disorder. Development and Psychopathology, 5, 63-78.

\title{
Effective Practices for Students with Learning Disabilities: Meeting the Challenges of the 21st Century
}

\author{
October 14-16, 1999 \\ Minneapolis, Minnesota \\ Radisson Hotel South \& Plaza Tower (Bloomington)
}

CLD's 21st International Conference on Learning Disabilities brings unparalleled professional growth opportunities for special and general teachers, school administrators, teacher educators, field researchers, and related services providers. Over the three days, keynote sessions, distinguished lectures, preconference workshops, mini-workshops, panels, concurrent breakout sessions, and small group discussions will focus on cutting-edge research, validated interventions, strategies and innovative policies and practices.

In addition, the Twin Cities offer many of the finest things in life, from shopping (the Mall of America is only a short shuttle ride from the convention hotel!), to theater and music (Minneapolis ranks second only to New York City in total number of live theater seats per capita, number of theaters in the area, and number of symphony concerts per year!), to sports, museums, galleries, fine dining, and more.

To receive complete registration information, please contact:

Council for Learning Disabilities, Box 40303, Overland Park, KS 66204

913/492-8755, or visit our web site: coe/winthrop.edu/cld

GET READY FOR THE NEW MILLENNIUM

JOIN YOUR COLLEAGUES IN THE TWIN CITIES

October 14-16 